Title: Development of an Antiseizure Drug Screening Platform for Dravet Syndrome at the NINDS contract site for the Epilepsy Therapy Screening Program

Authors: Chelsea D. Pernici ${ }^{1,2}$, Jeffrey A. Mensah ${ }^{2}$, Elizabeth J. Dahle ${ }^{1,2}$, Kristina J. Johnson ${ }^{1}$, Laura Handy $^{1}$, Lauren Buxton ${ }^{1,2}$, Misty D. Smith ${ }^{1,2}$, Peter J. West ${ }^{1,2}$, Cameron S. Metcalf ${ }^{1,2}$, Karen S. Wilcox ${ }^{1,2} *$

\title{
Author Affiliations:
}

${ }^{1}$ Epilepsy Therapy Screening Program (ETSP) Contract Site, University of Utah, Salt Lake City, Utah

${ }^{2}$ Department of Pharmacology and Toxicology, University of Utah, Salt Lake City, Utah *Corresponding Author

Correspondence: Karen S. Wilcox, Pharmacology and Toxicology, L.S. Skaggs Hall, 30 S 2000 E, Salt Lake City, UT 84112, 801-581-6287, karen.wilcox@hsc.utah.edu

Keywords: genetics; voltage gated sodium channel; mouse model; hyperthermia inducedseizures;

Number of Text Pages: 21

Number of words: 3980

Number of Figures: 4

Number of Tables: 2

Supporting Information Included 
Pernici, 2

\section{Summary:}

Objective: Dravet syndrome (DS) is a rare, but catastrophic genetic epilepsy, with $80 \%$ of patients with carrying a mutation in the SCN1A gene. Currently, no anti-seizure drug (ASD) exists that adequately controls seizures. Patients with DS often present clinically with a febrile seizure and generalized tonic-clonic seizures that continue throughout life. To facilitate the development of ASDs for DS, the contract site of the NINDS Epilepsy Therapy Screening Program (ETSP) has evaluated a mouse model of DS using the conditional knock-in Scnla $a^{A 1783 V / W T}$ mouse.

Methods: Survival rates and temperature thresholds for Scnla $a^{A 1783 V / W T}$ were determined. Prototype ASDs were administered via intraperitoneal injections at the time-to-peak effect, which was previously determined, prior to the induction of hyperthermia-induced seizures. Protection was determined if ASDs significantly increased the temperature at which Scnla $a^{A 1783 V / W T}$ mice seized.

Results: Approximately $50 \%$ of $S c n 1 a^{A 1783 V / W T}$ survive to adulthood and all have hyperthermiainduce seizures. The results suggest that hyperthermia-induced seizures in this model of DS are highly refractory to a battery of ASDs. Exceptions were clobazam, tiagabine, and the combination of clobazam and valproic acid with add-on stiripentol, which elevated seizure thresholds

Significance: Overall, the data demonstrate the proposed model for DS is suitable for screening novel compounds for the ability to block hyperthermia-induced seizures and heterozygous mice can be evaluated repeatedly over the course of several weeks, allowing for higher throughput screening. 
Keywords: genetics; voltage gated sodium channel; mouse model; hyperthermia inducedseizures;

Key Points:

- Scnla $a^{A 1783 V / W T}$ mice have a 50\% survival rate and all have hyperthermia-induced seizures.

- Common DS treatments such as CLB and combinatorial therapy of CLB, VPA, and STP increase temperature thresholds in $S c n 1 a^{A 1783 V / W T}$ mice.

- Sodium channel blockers, such as CBZ and LTG, decrease temperature thresholds of Scnla $a^{A 1783 V / W T}$ mice as predicted.

- Scnla $a^{A 1783 V / W T}$ mice are highly pharmacoresitant to common ASDs

- The Scnla $a^{A 1783 V / W T}$ may be a useful preclinical drug screening platform for the treatment of DS.

\section{Introduction:}

Dravet Syndrome (DS) is a rare, catastrophic form of genetic epilepsy manifesting in the first year of life of a seemingly normal infant ${ }^{1}$. In $80 \%$ of cases, the disease is caused by a mutation in the SCN1A gene, which encodes for the voltage-gated sodium channel Nav1.1 ${ }^{2}$. There are over 900 distinct SCN1A mutations, with a large percent resulting from missense or frameshift mutations, leading to a loss of function in the sodium channel ${ }^{3}$. In mouse models, the Scnla mutation has shown reduce sodium currents and excitability in inhibitory interneurons ${ }^{4-7}$. As a result, this causes an imbalance between inhibition and excitation, leading to general hyperexcitability. Seizures in humans are usually first induced by a fever or other increases in core temperature ${ }^{2}$. Spontaneous seizures will begin occurring within weeks of the initial seizure, becoming progressively worse and occurring more frequently ${ }^{8}$. Besides high seizure burden, DS also negatively impacts development and behavior and, in some cases, results in sudden 
unexpected death in epilepsy (SUDEP). DS is highly pharmacoresistant, with the primary treatment goal to decrease the seizure frequency and prevent status epilepticus ${ }^{9}$. Current treatment options fail to adequately address both seizures and the comorbidities associated with DS in many patients, and therefore discovering effective anti-seizure drugs (ASDs) is imperative. Typical first-line treatments for DS include valproate and clobazam, while stiripentol and topiramate are secondary lines of treatment, usually used congruently with valproate and clobazam $^{10-12}$. Both cannabidiol and fenfluramine are promising new therapeutics in DS patients, with cannabidiol reducing motor seizures by $\sim 40 \%{ }^{13,14}$ and fenfluramine reducing seizures by $\sim 50 \%{ }^{15-17}$. Some commonly used ASDs for seizure control, such as carbamazepine and lamotrigine, exacerbate seizures in both children and mice with DS conferring mutations ${ }^{8,18}$. These sodium channel blockers worsen seizures in patients due to reduced SCN1A function in inhibitory neurons, thereby promoting hyperexcitability ${ }^{8}$. While there have been recent advances in treatment options for patients with DS, full seizure freedom has yet to be achieved. Clinically relevant animal models with good face, construct, and predictive validity are critically needed to successfully screen and discover effective, novel therapies.

An important goal at the National Institutes of Neurological Disorders and Stroke (NINDs) contract site for the Epilepsy Therapy Screening Program (ETSP) is to have wellcharacterized, reliable, and translatable models to facilitate the development of novel therapies for the treatment of epilepsy, including genetic epilepsies such as DS. In order to develop a screening model for DS for potential adoption by the program, mice with a mutation in Scnla were obtained from Jackson Laboratories. The mutation mini-cassette includes lox P sites and, in the presence of Cre recombinase, results in an amino-acid substitution from alanine to valine at position $1783(\mathrm{~A} 1783 \mathrm{~V})$, previously reported in patients with $\mathrm{DS}^{19,20}$. This mutation in mice 
results in both hyperthermia-induced seizures, which mimics febrile seizures seen in a clinical setting, and spontaneous, recurrent seizures ${ }^{21-23}$. In the present study, we show the potential of using the hyperthermia-induced seizure phenotype to rapidly screen novel therapeutics for the treatment of DS. To characterize this model, a survival analysis and a temperature threshold at which heterozygous $\left(S c n 1 a^{A l 783 V / W T}\right)$ mice seize was determined. Following these experiments, a battery of ASDs for the treatment of epilepsy was administered to identify the pharmacological characteristics of this preclinical model. These data will serve as a metric for the identification of novel anti-seizure compounds.

\section{Methods}

\section{Animals}

All animal care and experimental procedures were approved by the Institutional Animal Care and Use Committee of the University of Utah. Animal experiments were conducted in a manner consistent with Animal Research: Reporting of In Vivo Experiments (ARRIVE) guidelines (https://www.nc3rs.org.uk/arrive-guidelines). Experimental animals were generated by breeding a floxed stop male Scnla ${ }^{\mathrm{A} 1783 \mathrm{~V}}$ (B6(Cg)-Scn1atm1.1Dsf/J, Jax \#026133) with a Sox2-cre (B6.Cg-Edil3 ${ }^{\operatorname{Tg}(\text { Sox2-cre)1Amc } / J) ~ f e m a l e ~ m o u s e ~ t o ~ p r o d u c e ~ b o t h ~ h e t e r o z y g o u s ~}\left(S c n 1 a^{A 1783 V / W T}\right)$ and wild-type offspring. Both female and male heterozygous and age-matched wild type littermates were used for experiments (4-6 weeks of age). Mice were group housed in a pathogen free facility under a 12-h light/12-h dark light cycle and had access to food and water ad-libitum, except during hyperthermia-induced seizure experiments, in which case, they were transferred to the experimental room approximately one hour before testing. 
Pernici, 6

To evaluate the temperature at which $S c n 1 a^{A 1783 V / W T}$ mice seize, mice were placed under a heat lamp and core temperature was gradually raised in a plexiglass chamber until a generalized seizure was observed or the temperature reached $42.5^{\circ} \mathrm{C}^{18,24-26}$. After the procedure, mice were transferred to a cool, granite block to rapidly lower the core temperature and then returned to their home cages. Body temperature was monitored using a neonate rectal probe (Braintree Scientific, Inc, Braintree, MA) coupled to a TCAT-2LV controller (Physitemp Instruments, Inc, Clifton, NJ). Mice acclimated in the chamber for 5 minutes prior to experiments. Male and female $S c n 1 a^{A 1783 V / W T}$ randomly received drug or vehicle prior to the test and staff were blinded to the treatment. The temperature at which mice seized was recorded. In experiments where wildtype mice were used, staff was also blinded to genotype.

\section{Drug preparation and administration}

Carbamazepine, clobazam, clonazepam, phenobarbital, phenytoin, stiripentol, and valproic acid were purchased from Sigma. Levetiracetam, lamotrigine, tiagabine, topiramate, fenfluramine, and rufindamide were obtained from TCI America (Portland, OR, U.S.A). Cannabidiol was purchased from Cayman Chemical (Ann Harbor, MI, U.S.A). Ezogabine and lacosamide were purchased from Axon Medchem (Reston, VA, U.S.A). For acute administration, all drugs were prepared as $0.5 \%$ methyl cellulose (Sigma; St. Louis, MO, U.S.A) suspensions. All drugs were administered in a volume of $0.01 \mathrm{~mL} / \mathrm{g}$. The dose $(\mathrm{mg} / \mathrm{kg})$ for each drug is listed in Table 1. All drug compounds were administered and tested based on their time-of-peak effect (TPE), which was previously determined in the maximal electroshock seizure (MES) model or in the $6 \mathrm{~Hz}$ test (data not shown). Intraperitoneal (i.p.) injections were administered at the TPE for each drug, which are listed in Table 1, prior to testing. For 5-day sub-chronic administration, compounds were administered at the same time each day and, on the last day, was administered at the TPE 
prior to hyperthermia-induced seizure testing. For the triple therapy study, clobazam and stiripentol were administered at $1.0 \mathrm{hr}$ as a single injection and valproic acid was administered $0.25 \mathrm{hr}$ in a separate injection prior to testing. In all testing, experimenters were blinded to treatment group and mice randomly assigned to treatment group.

\section{Cross-over studies}

For cross-over studies, an initial cohort of 4-week-old Scnla $a^{A 1783 V / W T}$ mice were randomly assigned into 2-3 treatment groups, including one vehicle group. The following week, mice were crossed over to another treatment group. This process was repeated for a maximum of four weeks. At the completion of testing, each mouse had received all treatments.

\section{Statistical Analysis}

Statistical comparisons were conducted using a Log-rank (Mantel-Cox) test. Significance was defined as a p-value $<0.05$. All analysis was conducted with GraphPad Prism 8.0. Sample sizes and statistical results are reported in figure legends. Data is presented as mean \pm SD.

\section{Results}

\section{Female $\operatorname{Scn} 1 a^{A 1783 V / W T}$ mice exhibit greater mortality than male mice during development}

The Scnla $a^{t m 1.1 D s f}$ mouse has a conditional knock-in mutation that is expressed when exposed to cre recombinase. For all experiments, $S c n 1 a^{\text {tml.Dsf }}$ male mice were bred to female Sox2-cre mice. As a result of cre expression in oocytes, the offspring are either heterozygous for the $S c n 1 a$ mutation $\left(S c n 1 a^{A 1783 V / W T}\right)$ or wild type (WT). Both the heterozygous and wild-type offspring were assessed for survival and compared. Over 60 days, approximately $50 \%$ of the Scnla $a^{A 1784 V / W T}$ mice survived, while no deaths were observed in wild type littermates (Figure 1A). When survival was evaluated based on sex, male $S c n l a^{A 1783 V / W T}$ mice had a significantly higher survival rate $(60.0 \%)$ than female mice $(32.0 \%)$ by adulthood (Figure 1B). 
Pernici, 8

\section{Male and female $\operatorname{Scn} 1 a^{A 1783 V / W T}$ mice have similar temperature thresholds for \\ hyperthermia-induced seizures}

The temperature threshold for which both male and female $S c n 1 a^{A 1783 V / W T}$ mice seize was determined by subjecting mice to a steady increase in core temperature. Testing was discontinued when core temperature reached $42.5^{\circ} \mathrm{C}^{18,25,26}$. If no seizure occurred by $42.5^{\circ} \mathrm{C}$, the mouse was considered seizure-free. All evaluated Scnl $a^{A 1783 V / W T}$ mice had hyperthermia-induced seizures, with an average temperature threshold of $38.5 \pm 1.9{ }^{\circ} \mathrm{C}$. There was no evidence of seizure activity when the core temperature of wild type littermates was raised to $42.5^{\circ} \mathrm{C}$ (Figure 1C). To further evaluate if sex-dependent temperature thresholds exist, data was evaluated by sex. There was no significant difference between temperature thresholds for male $\left(38.6 \pm 1.8^{\circ} \mathrm{C}\right)$ and female $\left(38.7 \pm 1.7^{\circ} \mathrm{C}\right) \operatorname{Scn} 1 a^{A 1783 V / W T}$ mice (Figure 1D).

\section{$S c n 1 a^{A 1783 V / W T}$ mice can be used for several weeks of drug screening}

To determine if $S c n 1 a^{A 1783 V / W T}$ mice continue to have hyperthermia-induced seizures as they age and if mice could be used over the course of several weeks for drug screening of multiple therapeutics, a crossover testing scheme was utilized. Mice were randomly divided into three initial treatment groups (vehicle, CLB (10 mg/kg), and CBZ (40 mg/kg)). At each week, CLB, a drug which reduces seizure frequency in patients with $\mathrm{DS}^{10}$, significantly increased the temperature at which $S c n l a^{A 1783 V / W T}$ mice had hyperthermia-induced seizures as compared to both vehicle and CBZ treated mice. On the other hand, CBZ, a drug which worsens seizures in patients with $\mathrm{DS}^{10}$, significantly decreased the temperature threshold at which $\operatorname{Scn} 1 a^{A 1783 V / W T}$ mice seized each week (Figure 2). Repeat treatment and repeat hyperthermia-induced seizures did not significantly affect the temperature at which $S c n 1 a^{A 1783 V / W T}$ mice seized (Supporting Figure 1) in each treatment group. 
Pernici, 9

\section{Evaluation of prototype ASDs against hyperthermia-induced seizures}

Additional ASDs that have previously shown efficacy in the treatment of DS, or those which are known to worsen seizure outcomes were evaluated against hyperthermia-induced seizures to determine the predictive validity of the Scnla ${ }^{A 1783 V / W T}$ mouse model. Of those drugs known to confer seizure protection in DS, both CBD and FFA were evaluated ${ }^{13,27,28}$. CBD (200 mg/kg) did not significantly increase the temperature at which hyperthermia-induced seizures occurred (Table 2). FFA was evaluated at two doses, $10 \mathrm{mg} / \mathrm{kg}$ and $25 \mathrm{mg} / \mathrm{kg}$. Neither dose had a significant effect on temperature threshold in $S c n 1 a^{A 1783 V / W T}$ mice (Supporting Figure 2 A\&B, Table 2).

Sodium channel blockers such as CBZ and LTG can increase the frequency or severity of seizures in patients with $\mathrm{DS}^{10} .40 \mathrm{mg} / \mathrm{kg} \mathrm{CBZ}$ significantly lowered the temperature at which hyperthermia-induced seizures occurred (Figure 2A-D). LTG was tested as a single $10 \mathrm{mg} / \mathrm{kg}$ dose and had no effect on the temperature threshold (Supporting Figure 2C, Table 2). However, when $20 \mathrm{mg} / \mathrm{kg}$ LTG was sub-chronically administered daily for 5 days and a hyperthermia-induced seizure was conducted on Day 5, it significantly lowered the temperature threshold as compared to vehicle treated mice. Additionally, during the 5-Day administration of LTG, 2 of the 6 mice in the treatment group died (Supporting Figure 2D).

\section{Except for tiagabine, hyperthermia-induced seizures in $S c n 1 a^{A 1783 V / W T}$ mice are refractory to a battery of anti-seizure drugs}

In addition to the compounds evaluated above, other prototype ASDs used in the treatment of epilepsy were evaluated. Of these additional compounds, only TGB was found to be effective in shifting the temperature threshold at which seizures occurred. TGB, which has shown to be protective against hyperthermia-induced seizures in a haploinsufficient mouse model of $\mathrm{DS}^{29}$, 
was evaluated at $1.3 \mathrm{mg} / \mathrm{kg}, 3 \mathrm{mg} / \mathrm{kg}$, and $5 \mathrm{mg} / \mathrm{kg}$. At all doses, TGB significantly increased the temperature at which mice seized as compared to vehicle (Figure $\mathbf{3 A}-\mathbf{C}$ ). At $1.3 \mathrm{mg} / \mathrm{kg}, 1$ out of 10 treated mice was fully protected, at $3 \mathrm{mg} / \mathrm{kg}, 3$ out of 9 treated mice were fully protected and at $5 \mathrm{mg} / \mathrm{kg}, 3$ out of the 9 treated mice had complete protection against hyperthermia-induced seizures. None of the other ASDs listed in Table 2 significantly affected the temperature threshold at which $S c n 1 a^{A 1783 V / W T}$ mice had a hyperthermia-induced seizure $(\mathrm{p}>0.05$, Log-rank (Mantel-Cox)), suggesting this model of DS is highly refractive to a battery of ASDs.

\section{Evaluation of add-on treatment against hyperthermia-induced seizures}

First line treatment of DS includes either CLB or VPA ${ }^{30}$. When either fails as independent treatment, CLB and VPA are administered together ${ }^{11}$. Stand-alone treatment of either $5 \mathrm{mg} / \mathrm{kg}$ CLB or $300 \mathrm{mg} / \mathrm{kg}$ VPA did not offer significant protection against hyperthermia-induced seizures in Scnla $a^{A 1783 V / W T}$ mice (Table 2). Therefore, as done in the clinic, CLB and VPA were administered congruently. $5 \mathrm{mg} / \mathrm{kg}$ CLB and $150 \mathrm{mg} / \mathrm{kg}$ VPA significantly raised the temperature threshold compared to vehicle treated mice (Figure 4A). If this combination fails in the clinic, a relevant second-line drug regimen combines CLB and VPA with STP as an add-on drug $^{11}$. We tested a combination of $5 \mathrm{mg} / \mathrm{kg}$ CLB and $75 \mathrm{mg} / \mathrm{kg}$ which did not offer significant protection (Figure 4B). To mimic what is done in the clinic, $100 \mathrm{mg} / \mathrm{kg} \mathrm{STP}$ was then "added on" to $5 \mathrm{mg} / \mathrm{kg}$ CLB and $75 \mathrm{mg} / \mathrm{kg}$ VPA treatment. The CLB $(5 \mathrm{mg} / \mathrm{kg})+$ VPA $(75 \mathrm{mg} / \mathrm{kg})+$ STP (100 mg/kg) treated mice had significantly higher temperature thresholds than CLB (5 $\mathrm{mg} / \mathrm{kg})+\operatorname{VPA}(75 \mathrm{mg} / \mathrm{kg})$ treated Scnla $a^{A 1783 V / W T}$ mice (Figure 4C). Finally, we show that a lower dose of add-on STP does significantly raise temperature thresholds as compared to the combination of CLB (5 mg/kg) and VPA (75 mg/kg) (Figure 4D). Thus, this add-on screening 
Pernici, 11

approach may prove useful when screening novel compounds for efficacy against hyperthermia induced seizures.

\section{Discussion:}

Drug resistant epilepsies, like DS, critically need preclinical drug screening models to identify effective compounds. There are over 900 distinct mutations that result in this highly complex encephalopathy, further necessitating the availability of translatable models to discover effective therapies. Introducing new screening models to the Epilepsy Therapy Screening Program requires understanding both the face and predictive validity of proposed models. The Scnla $a^{A 1783 V / W T}$ model has a survival rate of $\sim 50 \%$ (Figure 1A\&B), demonstrating the Scnla $a^{A 1783 V / W T}$ mouse model has at least as good or better viability than other models, increasing the yield of experimental mice $e^{4,22,31}$. Scnla $a^{A 1783 V / W T}$ mice maintain the hyperthermia-induced seizure phenotype (Figure 1C\&D) as they age (Figure 2). While males have a significantly higher survival rate than females (Figure 1B) there was no difference in the temperatures at which they seized (Figure 1D). The breeding scheme used here allows for approximately half the offspring to be heterozygous for the mutation. This allows for faster breeding than in other models, especially as the breeding pairs, who do not express the floxed transgene, survive readily. The predictive validity of this model should be well characterized prior to screening novel compounds, as this provides a baseline metric from which to determine if novel compounds have superior efficacy over available compounds. Clinically approved ASDs for the treatment of DS, ASDs that are contradicted, as well as a battery of other ASDs, were screened to pharmacologically profile the $S c n 1 a^{A 1783 V / W T}$ mouse model.

A first-line treatment for DS is $\mathrm{CLB}^{10}$. We found $10 \mathrm{mg} / \mathrm{kg}$ CLB significantly increased the temperature at which $\operatorname{Scn} 1 a^{A 1783 V / W T}$ mice seized (Figure 2). CLB has also been tested against 
hyperthermia-induced seizures in the F1.Scnla $a^{\text {tmlKea }}$ mouse and $5 \mathrm{mg} / \mathrm{kg}$ CLB conferred protection $^{18}$. In another study, single injections of CLB at $1 \mathrm{mg} / \mathrm{kg}$ and $10 \mathrm{mg} / \mathrm{kg}$ both significantly increased the temperature threshold of the F1.Scnla ${ }^{\text {tmlKea }}$ mouse $^{26}$. In a mouse model with a truncation mutation, $S c n 1 a^{R 1407 X}, 6.62 \mathrm{mg} / \mathrm{kg}$ CLB also significantly increased the temperature at which mice had hyperthermia-induced seizures ${ }^{32}$. Overall, CLB has been effective against spontaneous seizures in patients ${ }^{30}$ and against hyperthermia-induced seizures in, along with the data obtained herein, three DS mouse models.

CBD, which was recently approved by the FDA as an adjunct to conventional ASDs, significantly reduces seizure frequency in patients ${ }^{13,28}$. In the clinic, CBD is used as add-on therapy to currently prescribed treatment, with $66 \%$ of patients using it concomitantly with $\mathrm{CLB}^{28}$. In this present study, we tested CBD as a monotherapy and found $200 \mathrm{mg} / \mathrm{kg} \mathrm{CBD}$ did not offer significant protection (Table 2). While there was no protective effect in this model at the dose and time point tested, CBD monotherapy showed significant protection in two other DS mouse models. When $100 \mathrm{mg} / \mathrm{kg}$ CBD was administered to the F1.Scnla ${ }^{\text {tmlKea }}$ mouse it significantly increased the temperature at which mice seized ${ }^{26}$ and when administered to the $\mathrm{Scn} \mathrm{a}^{+/-}$null mouse at both $100 \mathrm{mg} / \mathrm{kg}$ and $200 \mathrm{mg} / \mathrm{kg}, \mathrm{CBD}$ significantly reduced seizure length and severity ${ }^{33}$. In the F1.Scnla ${ }^{\text {tmlKea }}$ mouse, the combination of $10 \mathrm{mg} / \mathrm{kg} \mathrm{CLB}$ and $12 \mathrm{mg} / \mathrm{kg}$ CBD significantly increased the temperature threshold as compared to CBD monotherapy, suggesting the combination therapy may be more beneficial. Additionally, as not all people with DS have their seizures suppressed by CBD, not all mouse models of DS are protected from hyperthermia-induced seizures.

When treating DS, sodium channel blockers, such as CBZ and LTG, are avoided, as these can make seizure frequency and severity worse ${ }^{9,34}$. In $S c n l a^{A l 783 V / W T}$ mice, a single injection of 
$40 \mathrm{mg} / \mathrm{kg} \mathrm{CBZ}$ significantly lowered the temperature at which mice seized (Figure 2). While a single dose of $10 \mathrm{mg} / \mathrm{kg}$ LTG had no effect on threshold temperatures (Supporting Figure 2C, Table 2), sub-chronic administration of $20 \mathrm{mg} / \mathrm{kg}$ LTG over the course of 5 days significantly lowered the temperatures at which mice seized and two mice died due to treatment (Supporting Figure 2D, Table 2). Both CBZ and LTG were tested in the F1.Scnla $a^{\text {tmlKea }}$ model, but a single dose of $20 \mathrm{mg} / \mathrm{kg}$ LTG significantly lowered temperature threshold, while $20 \mathrm{mg} / \mathrm{kg} \mathrm{CBZ} \mathrm{had} \mathrm{no}$ effect. While our study did not include single administration of $20 \mathrm{mg} / \mathrm{kg}$ LTG, we presume it would also lower the temperature threshold, much like observed in the F1. Scn $1 a^{\text {tmlKea }}$. The CBZ doses differed between the two studies, which could contribute to the difference seen in the temperature thresholds. However, given that our results align with what is seen in the clinical setting these compounds functioned as hypothesized in the Scnla $a^{A 1783 V / W T}$ mouse model.

A notable effect in the present study was TGB conferred protection against hyperthermia-induced seizures in $S c n l a^{A 1783 V / W T}$ (Figure 3). This is consistent with the pharmacological profile in a haploinsufficiency mouse model, as a high dose (10 mg/kg) significantly protected mice against generalized tonic-clonic seizures during hyperthermia testing ${ }^{29}$. While we saw significant protection in our model, with minimal toxic side effects, in patients, TGB is associated with behavioral side effects and reports of nonconvulsive absence and myoclonic seizures associated with TGB treatment ${ }^{35}$. Therefore, NICE guidelines recommend against using TGB for treatment of DS.

Other compounds used to treat some patients with DS, such as LEV and TPM, did not significantly confer protection in the $S c n l a^{A 1783 V / W T}$ model (Table 2). However, in the F1.Scn la ${ }^{\text {tmlKea }}$ mouse model, $10 \mathrm{mg} / \mathrm{kg}$ LEV significantly increased temperature thresholds and $40 \mathrm{mg} / \mathrm{kg}$ TPM also showed no effect. LEV is only used when no other first-line treatment is 
successful $^{30}$, with responder rates anywhere between $11 \%-64 \%^{36,37}$. It's not as surprising to discover this particular compound was effective in one mouse model and not the other, as there seems to be variability in the efficacy of this particular drug.

While CLB is commonly used in the treatment of DS, it's responder rate is $\sim 28 \%{ }^{30}$ and add-on treatments are normally required to obtain adequate seizure control. These include the addition of drugs such as VPA and STP. $300 \mathrm{mg} / \mathrm{kg}$ VPA monotherapy did not offer significant protection as compared to vehicle treated mice (Table 2). Thus, we combined $5 \mathrm{mg} / \mathrm{kg}$ CLB and $150 \mathrm{mg} / \mathrm{kg}$ VPA and found it conferred significant protection (Figure 4A). We decreased the dose of VPA to $75 \mathrm{mg} / \mathrm{kg}$, while maintaining CLB at a dose of $5 \mathrm{mg} / \mathrm{kg}$ and found it no longer significantly protected Scnla $a^{A 1783 V / W T}$ mice (Figure 4B). When the combination of CLB and VPA fails in the clinic, STP is added to the treatment regimen ${ }^{11}$. We administered $5 \mathrm{mg} / \mathrm{kg}$ CLB, $75 \mathrm{mg} / \mathrm{kg}$ VPA, and $100 \mathrm{mg} / \mathrm{kg}$ STP and found this significantly offered protection as compared to $5 \mathrm{mg} / \mathrm{kg}$ CLB and $75 \mathrm{mg} / \mathrm{kg}$ VPA treatment (Figure 4C). We found this triple drug therapy to be effective and supports this pharmacological treatment regimen for DS. The combined use of CLB and VPA with an add-on investigational compound may be a useful approach towards novel therapy screening in this mouse model of DS.

Additional compounds were tested against hyperthermia-induced seizures in the Scnla $a^{A 1783 V / W T}$ mouse model. Much like what is observed in the clinical setting with patients, this model is highly pharmacoresistant. However, as the majority of these experiments were all performed with acute injections, it might prove useful to determine the effect of these compounds when sub-chronically administered at doses sufficient to provide steady state therapeutic brain and plasma levels. Nevertheless, those experiments are technically challenging given the stress of multiple injections per day over the course of several days. Therefore, sub 
chronic dosing, wherein drugs can be delivered in food, would be a potential approach to addressing the limitations inherent in performing sub chronic dosing experiments with injections.

Another phenotype of DS is spontaneous, recurrent seizures. Drugs effective in patients, such as treatment with CBD (Table 2) and FFA (Supporting Figure 2A\&B, Table 2), may be effective at reducing spontaneous seizure frequency in this mouse model or require chronic dosing in hyperthermia studies. In fact, when a patient presents in the clinic with a febrile seizure, they are typically administered rescue treatment, such as diazepam or midazolam. If patients are then diagnosed with DS, they are started on regimen of ASDs. Therefore, because a drug was not protective against hyperthermia-induced seizures does not necessarily mean it will not be effective against spontaneous seizures. Studies where conventional ASDs were screened in other mouse models of DS, variable results between hyperthermia-induced and spontaneous seizures were achieved. In the F1.Scnla ${ }^{\text {tmlKea }}$ mouse model, CLB was protective against hyperthermia-induced seizures, but had minimal effect against spontaneous seizures ${ }^{18}$. Surprisingly, in the F1.Scnla $a^{\text {tmlKea }}$, mouse, CBZ had no effect on either hyperthermia-induced or spontaneous seizures, while we saw a significant effect in lowering the temperature threshold of hyperthermia-induced seizures ${ }^{18}$. In another study using the F1.Scn $1 a^{\text {tmlKea }}$ mouse, monotherapy CBD significantly increased the temperature threshold of mice, yet had no effect on spontaneous seizure frequency ${ }^{26}$. Therefore, it's possible there is a pharmacological difference between hyperthermia-induced and spontaneous seizures, which may explain a lack of translation of some compounds to the clinic. In order to find effective therapies, novel therapeutics may also need to be screened against spontaneous seizures. Nonetheless, using hyperthermia-induced seizures is still an important screening platform as due to its highly pharmaco-resistant nature, we may be able to uncover extremely effective drugs. 
Beyond the differences that may exist between hyperthermia-induced and spontaneous seizures at a pharmacological level, there are over 900 distinct mutations that result in $\mathrm{DS}^{20}$, making this form of epilepsy highly patient specific. Consequently, it is possible that mice will respond differently to ASDs when exhibiting different mutations. This could explain why some of the ASDs have shown to be effective against hyperthermia-induced seizures in the present model, which results from a missense mutation, and not in the F1.Scnl $a^{\text {tmlKea }}$ mouse, a model of haploinsufficiency. Therefore, we not only need translatable models for hyperthermia-induced and spontaneous seizures, but it would also be beneficial to have well characterized models for the different mutations.

An additional approach to screening novel compounds for DS is the use of zebrafish larvae. While zebrafish larvae do not recapitulate all the aspects of DS, such as cognitive disabilities, the $s c n 1 a^{\mathrm{s} 552}$ larvae exhibit unprovoked seizures ${ }^{38}$. This particular model has been validated with a number of ASDs and suppression of unprovoked seizure activity was achieved with commonly prescribed drugs for patients with $\mathrm{DS}^{39}$, while drugs such as sodium channel blockers, increased seizure activity. This model is particularly advantageous as high throughput with short assay times is achieved, allowing rapid screening of novel compounds, a significant advantage over mouse models. In fact, lorcaserin, which has shown efficacy in some DS patients, was identified in zebrafish larvae ${ }^{40}$, further demonstrating this model has a role in the discovery of treatments for DS.

Overall, this study sets a foundation for screening novel compounds developed for DS through the use of the $S c n 1 a^{A 1783 V / W T}$ model. While the $S c n 1 a^{A 1783 V / W T}$ mouse did not respond to all drugs used as treatments for DS, the hyperthermia-induced seizure phenotype was highly pharmacoresistant, suggesting this model could lead to the discovery of novel and robust 
compounds for the treatment of DS, especially when paired with CLB and VPA treatment, as is done clinically.

Acknowledgements: The authors thank the Epilepsy Therapy Screening Program at the National Institutes of Neurological Disease and Stroke for their review and comments on this manuscript. The authors would like to thank Jennifer Kearney for helpful discussions. This project has been funded by Federal funds from the National Institute of Neurological Disorders and Stroke, Epilepsy Therapy Screening Program, National Institutes of Health and Department of Health and Human Services, under Contract No. HHSN271201600048C.

Disclosure of Conflicts of Interest: None of the authors has any conflict of interest to disclose.

We confirm that we have rea the Journal's position on issues involved in ethical publication and affirm that this report is consistent with those guidelines.

\section{References}

1. Martin P, Rautenstraubeta B, Abicht A, et al. Severe Myoclonic Epilepsy in Infancy Adult Phenotype with Bradykinesia, Hypomimia, and Perseverative Behavior: Report of Five Cases. Mol Syndromol. 2010;1:231-238.

2. Dravet C. The core Dravet Syndrome phenotype. Epilepsia. 2011 Apr;52 Suppl 2:3-9.

3. Depienne C, Trouillard O, Saint-Martin C, et al. Spectrum of SCN1A gene mutations associated with Dravet Syndrome: analysis of 333 patients. J Med Genet. 2009 Mar;46:183-191.

4. Yu FH, Mantegazza M, Westenbroek RE, et al. Reduced sodium current in GABAergic interneurons in a mouse model of severe myoclonic epilepsy in infancy. Nat Neurosci. 2006 Sep;9:1142-1149. 
5. Tai C, Abe Y, Westenbroek RE, et al. Impaired excitability of somatostatin- and parvalbumin-expressing cortical interneurons in a mouse model of Dravet Syndrome. Proc Natl Acad Sci U S A. 2014 Jul 29;111:E3139-3148.

6. Rubinstein M, Westenbroek RE, Yu FH, et al. Genetic background modulates impaired excitability of inhibitory neurons in a mouse model of Dravet Syndrome. Neurobiol Dis. 2015 Jan;73:106-117.

7. Favero M, Sotuyo NP, Lopez E, et al. A Transient Developmental Window of FastSpiking Interneuron Dysfunction in a Mouse Model of Dravet Syndrome. J Neurosci. 2018 Sep 5;38:7912-7927.

8. Catterall WA. Dravet Syndrome: A Sodium Channel Interneuronopathy. Curr Opin Physiol. 2018 Apr;2:42-50.

9. Chiron C, Dulac O. The pharmacologic treatment of Dravet Syndrome. Epilepsia. 2011 Apr;52 Suppl 2:72-75.

10. Wirrell EC, Nabbout R. Recent Advances in the Drug Treatment of Dravet Syndrome. CNS Drugs. 2019 Sep;33:867-881.

11. Cross JH, Caraballo RH, Nabbout R, et al. Dravet Syndrome: Treatment options and management of prolonged seizures. Epilepsia. 2019 Dec;60 Suppl 3:S39-S48.

12. Morimoto M, Shimakawa S, Hashimoto T, et al. Marked efficacy of combined three-drug therapy (Sodium Valproate, Topiramate and Stiripentol) in a patient with Dravet Syndrome. J Clin Pharm Ther. 2018 Aug;43:571-573.

13. Devinsky O, Nabbout R, Miller I, et al. Long-term cannabidiol treatment in patients with Dravet Syndrome: An open-label extension trial. Epilepsia. 2019 Feb;60:294-302. 
14. Laux LC, Bebin EM, Checketts D, et al. Long-term safety and efficacy of cannabidiol in children and adults with treatment resistant Lennox-Gastaut syndrome or Dravet syndrome: Expanded access program results. Epilepsy Res. 2019 Aug;154:13-20.

15. Ceulemans B, Boel M, Leyssens K, et al. Successful use of fenfluramine as an add-on treatment for Dravet Syndrome. Epilepsia. 2012 Jul;53:1131-1139.

16. Ceulemans B, Schoonjans AS, Marchau F, et al. Five-year extended follow-up status of 10 patients with Dravet Syndrome treated with fenfluramine. Epilepsia. 2016 Jul;57:e129-134.

17. Schoonjans A, Paelinck BP, Marchau F, et al. Low-dose fenfluramine significantly reduces seizure frequency in Dravet Syndrome: a prospective study of a new cohort of patients. Eur J Neurol. 2017 Feb;24:309-314.

18. Hawkins NA, Anderson LL, Gertler TS, et al. Screening of conventional anticonvulsants in a genetic mouse model of epilepsy. Ann Clin Transl Neurol. 2017 May;4:326-339.

19. Klassen TL, Bomben VC, Patel A, et al. High-resolution molecular genomic autopsy reveals complex sudden unexpected death in epilepsy risk profile. Epilepsia. 2014 Feb;55:e6-12.

20. Lossin C. A catalog of SCN1A variants. Brain Dev. 2009 Feb;31:114-130.

21. Kuo FS, Cleary CM, LoTurco JJ, et al. Disordered breathing in a mouse model of Dravet Syndrome. eLife. 2019 Apr 26;8.

22. Ricobaraza A, Mora-Jimenez L, Puerta E, et al. Epilepsy and neuropsychiatric comorbidities in mice carrying a recurrent Dravet Syndrome SCN1A missense mutation. Sci Rep. 2019 Oct 2;9:14172. 
23. Styr B, Gonen N, Zarhin D, et al. Mitochondrial Regulation of the Hippocampal Firing Rate Set Point and Seizure Susceptibility. Neuron. 2019 Jun 5;102:1009-1024 e1008.

24. Hawkins NA, Lewis M, Hammond RS, et al. The synthetic neuroactive steroid SGE-516 reduces seizure burden and improves survival in a Dravet Syndrome mouse model. Sci Rep. 2017 Nov 10;7:15327.

25. Anderson LL, Hawkins NA, Thompson CH, et al. Unexpected Efficacy of a Novel Sodium Channel Modulator in Dravet Syndrome. Sci Rep. 2017 May 10;7:1682.

26. Anderson LL, Absalom NL, Abelev SV, et al. Coadministered cannabidiol and clobazam: Preclinical evidence for both pharmacodynamic and pharmacokinetic interactions. Epilepsia. 2019 Nov;60:2224-2234.

27. Lagae L, Sullivan J, Knupp K, et al. Fenfluramine hydrochloride for the treatment of seizures in Dravet Syndrome: a randomised, double-blind, placebo-controlled trial. Lancet. 2020 Dec 21;394:2243-2254.

28. Devinsky O, Cross JH, Wright S. Trial of Cannabidiol for Drug-Resistant Seizures in the Dravet Syndrome. N Engl J Med. 2017 Aug 17;377:699-700.

29. Oakley JC, Cho AR, Cheah CS, et al. Synergistic GABA-enhancing therapy against seizures in a mouse model of Dravet Syndrome. J Pharmacol Exp Ther. 2013 May;345:215-224.

30. Wirrell EC. Treatment of Dravet Syndrome. Can J Neurol Sci. 2016 Jun;43 Suppl 3:S1318.

31. Miller AR, Hawkins NA, McCollom CE, et al. Mapping genetic modifiers of survival in a mouse model of Dravet Syndrome. Genes Brain Behav. 2014 Feb;13:163-172. 
32. Cao D, Ohtani H, Ogiwara I, et al. Efficacy of stiripentol in hyperthermia-induced seizures in a mouse model of Dravet Syndrome. Epilepsia. 2012 Jul;53:1140-1145.

33. Kaplan JS, Stella N, Catterall WA, et al. Cannabidiol attenuates seizures and social deficits in a mouse model of Dravet Syndrome. Proc Natl Acad Sci U S A. 2017 Oct $17 ; 114: 11229-11234$.

34. Guerrini R, Dravet C, Genton P, et al. Lamotrigine and seizure aggravation in severe myoclonic epilepsy. Epilepsia. 1998 May;39:508-512.

35. Koepp MJ, Edwards M, Collins J, et al. Status epilepticus and tiagabine therapy revisited. Epilepsia. 2005 Oct;46:1625-1632.

36. Dressler A, Trimmel-Schwahofer P, Reithofer E, et al. Efficacy and tolerability of the ketogenic diet in Dravet Syndrome - Comparison with various standard antiepileptic drug regimen. Epilepsy Res. 2015 Jan;109:81-89.

37. Striano P, Coppola A, Pezzella M, et al. An open-label trial of levetiracetam in severe myoclonic epilepsy of infancy. Neurology. 2007 Jul 17;69:250-254.

38. Dinday MT, Baraban SC. Large-Scale Phenotype-Based Antiepileptic Drug Screening in a Zebrafish Model of Dravet Syndrome. eNeuro. 2015 Jul-Aug;2.

39. Griffin A, Hamling KR, Hong S, et al. Preclinical Animal Models for Dravet Syndrome: Seizure Phenotypes, Comorbidities and Drug Screening. Front Pharmacol. 2018;9:573.

40. Griffin A, Hamling KR, Knupp K, et al. Clemizole and modulators of serotonin signalling suppress seizures in Dravet Syndrome. Brain. 2017 Mar 1;140:669-683. 
Table 1. List of prototype drugs evaluated in $S c n l a^{\mathrm{A} 1783 \mathrm{~V} / \mathrm{WT}}$ mice following intraperitoneal administration.

$\begin{array}{llll}\text { Drug } & \text { Dosing Strategy } & \text { Dose }(\mathbf{m g} / \mathbf{k g}) & \text { TPE }(\mathbf{h r}) \\ \text { Clobazam (CLB) } & \text { Single } & 2.5,5,10 & 1.0 \\ \text { Carbamazepine (CBZ) } & \text { Single } & 40 & 0.25 \\ \text { Cannabidiol (CBD) } & \text { Single } & 100,200 & 1.0 \\ \text { Clonazepam (CLN) } & \text { Single } & 0.5 & 0.5 \\ \text { Ezogabine (EZG) } & \text { Single } & 20 & 1.0 \\ \text { Fenfluramine (FFA) } & \text { Single } & 10,25 & 0.5 \\ \text { Lacosamide (LCM) } & \text { Single } & 15 & 0.5 \\ \text { Lamotrigine (LTG) } & \text { Single, sub-chronic } & 10,20 & 1.0 \\ \text { Levetiracetam (LEV) } & \text { Single } & 100 & 1.0 \\ \text { Lorcaserin } & \text { Single } & 10 & 0.5 \\ \text { Phenobarbital (PHB) } & \text { Single } & 15 & 0.5 \\ \text { Retigabine } & \text { Single } & 20 & 1.0 \\ \text { Rufinamide } & \text { Single } & 32 & 0.5 \\ \text { Stiripentol (STP) } & \text { Single } & 100 & 1.0 \\ \text { Tiagabine (TGB) } & \text { Single } & 1.3,3,5 & 1.0 \\ \text { Topiramate (TPM) } & \text { Single } & 300 & 1.0 \\ \text { Valproic Acid (VPA) } & \text { Single } & 300 & 0.25 \\ \text { CLB + VPA } & \text { Single } & 5,150 & 1.0,0.25 \\ \text { CLB + VPA } & \text { Single } & 5,75 & 1.0,0.25 \\ \text { CLB + VPA + STP } & \text { Single } & 5,75,100 & 1.0,0.25,1.0 \\ \text { CLB + VPA + STP } & \text { Single } & 5,75,30 & 1.0,0.25,1.0\end{array}$


Table 2. Anti-seizure drugs refractory to hyperthermia-induced seizures in $\operatorname{Scn}_{1 a^{A 1783 V / W T}}$ mice.

\begin{tabular}{|c|c|c|c|c|c|}
\hline Compound & $\begin{array}{c}\text { Dose } \\
(\mathbf{m g} / \mathbf{k g})\end{array}$ & $\begin{array}{c}\text { Vehicle } \\
\text { Temp }\left({ }^{\circ} \mathrm{C}\right)\end{array}$ & $\begin{array}{c}\text { Drug } \\
\text { Temp }\left({ }^{\circ} \mathrm{C}\right)\end{array}$ & $\begin{array}{c}\text { Efficacy } \\
\text { (\# Protected/N) }\end{array}$ & $\begin{array}{c}\text { Significance } \\
\text { (Log-rank) }\end{array}$ \\
\hline Clonazepam & $0.5^{\circ}$ & $39.1 \pm 2.0, n=10$ & $40.0 \pm 1.7, n=10$ & $0 / 10$ & $\mathrm{p}=0.2385$ \\
\hline Phenobarbital & 15 & $38.6 \pm 1.6, n=4$ & $39.3 \pm 1.0, \mathrm{n}=6$ & $0 / 6$ & $p=0.5789$ \\
\hline Lacosamide & 15 & $37.5 \pm 2.0, n=3$ & $37.1 \pm 1.4, \mathrm{n}=10$ & $0 / 10$ & $p=0.4098$ \\
\hline Levetiracetam & 100 & $38.8 \pm 1.9, n=10$ & $39.8 \pm 1.5, \mathrm{n}=10$ & $1 / 10$ & $p=0.2242$ \\
\hline Retigabine & 20 & $38.8 \pm 1.9, n=10$ & $38.7 \pm 1.7, n=10$ & $0 / 10$ & $p=0.8593$ \\
\hline Rufinamide & 32 & $39.2 \pm 1.5, \mathrm{n}=10$ & $39.4 \pm 1.5, n=9$ & $0 / 10$ & $p=0.8846$ \\
\hline Topiramate & 300 & $39.2 \pm 1.5, n=10$ & $39.3 \pm 1.7, n=9$ & $0 / 10$ & $p=0.7416$ \\
\hline Lorcaserin & 10 & $37.9 \pm 2.0, n=10$ & $37.6 \pm 2.4, n=10$ & $0 / 10$ & $p=0.6089$ \\
\hline \multirow[t]{2}{*}{ Clobazam } & 2.5 & $38.7 \pm 1.0, n=7$ & $39.6 \pm 0.7, n=9$ & $0 / 9$ & $p=0.1212$ \\
\hline & 5 & $38.7 \pm 0.4, n=7$ & $39.8 \pm 1.3, n=8$ & $1 / 8$ & $p=0.0564$ \\
\hline Stiripentol & 100 & $38.2 \pm 1.2, n=16$ & $37.8 \pm 1.3, \mathrm{n}=16$ & $0 / 16$ & $\mathrm{p}=0.849$ \\
\hline Valproic Acid & 300 & $39.5 \pm 1.2, \mathrm{n}=11$ & $40.2 \pm 1.0, n=11$ & $1 / 11$ & $\mathrm{p}=0.4677$ \\
\hline Cannabidiol & 200 & $39.0 \pm 1.5, n=10$ & $38.6 \pm 2.0, n=10$ & $1 / 10$ & $\mathrm{p}=0.8119$ \\
\hline \multirow[t]{2}{*}{ Fenfluramine } & 10 & $39.0 \pm 1.2, \mathrm{n}=9$ & $39.0 \pm 2.3, n=10$ & $0 / 10$ & $p=0.4862$ \\
\hline & 25 & $39.0 \pm 0.7, \mathrm{n}=10$ & $38.8 \pm 2.1, \mathrm{n}=10$ & $0 / 10$ & $\mathrm{p}=0.2480$ \\
\hline \multirow[t]{2}{*}{ Lamotrigine } & 10 & $37.9 \pm 2.0, n=9$ & $37.1 \pm 1.3, \mathrm{n}=9$ & $0 / 10$ & $\mathrm{p}=0.1898$ \\
\hline & 20, sub & $39.4 \pm 0.8, n=6$ & $37.6 \pm 0.9, n=4$ & $0 / 10$ & $p=0.0046$ \\
\hline
\end{tabular}


bioRxiv preprint doi: https://doi.org/10.1101/2020.12.01.406470; this version posted December 2, 2020. The copyright holder for this preprint (which was not certified by peer review) is the author/funder, who has granted bioRxiv a license to display the preprint in perpetuity. It is made available under aCC-BY-NC-ND 4.0 International license.

Pernici, 24

Data presented as mean \pm SD. Log-rank (Mantel-Cox). 
Pernici, 25
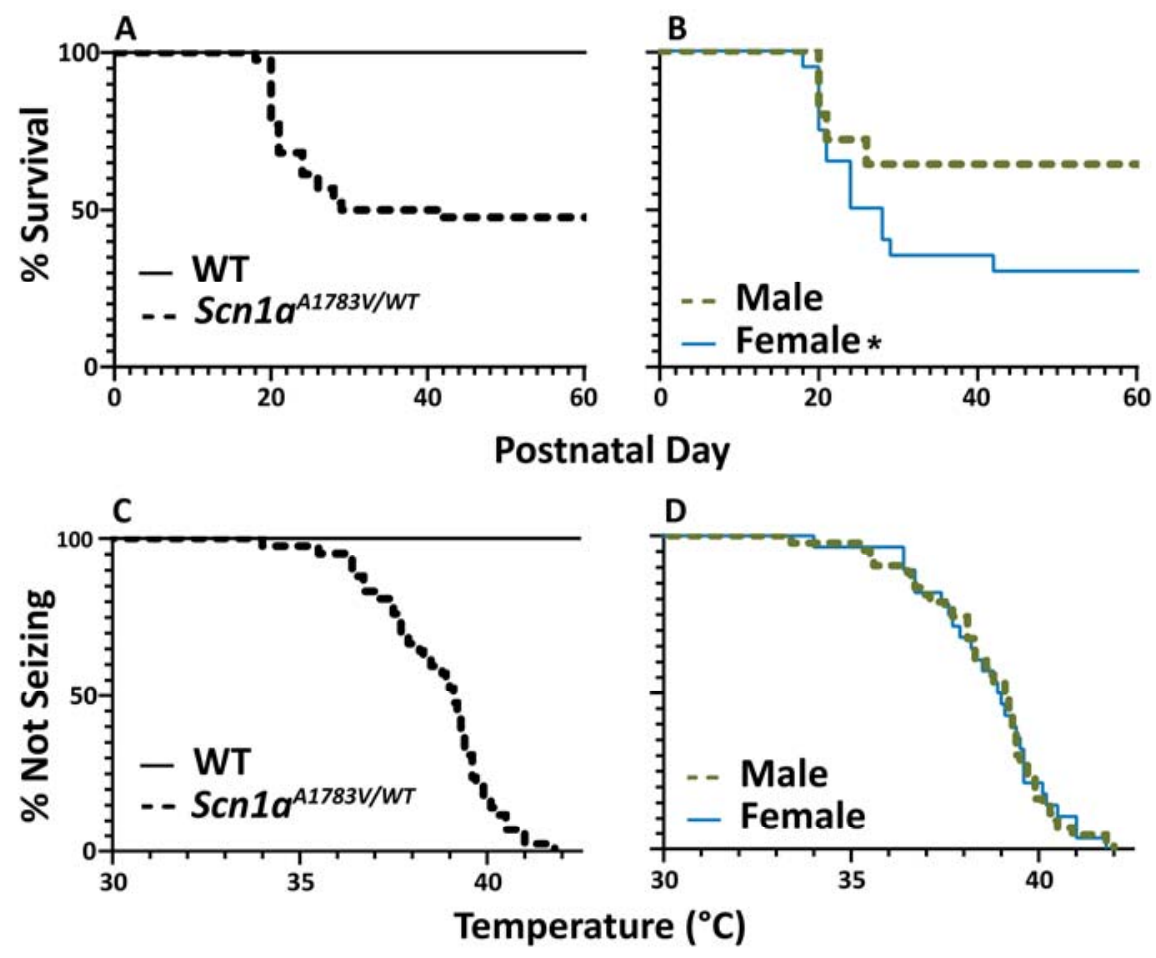

Figure 1. Approximately $50 \%$ of $S c n 1 a^{A 1783 V / W T}$ mice survive to adulthood and female $S c n 1 a^{A 1783 V / W T}$ mice exhibit greater mortality than male mice during development. A) By postnatal day $60,51.1 \%$ of the observed $S c n 1 a^{A 1783 V / W T}$ mice die, with the first death occurring at or around the age at which mice are weaned (P21). None of the wild type offspring died during the 60-day observation period (Scn1 $a^{A 1783 V / W T}$ : $\mathrm{n}=45$, WT: $\mathrm{n}=30$ ). B) When survival was evaluated based on sex, males had a significantly lower death rate $(32.0 \%)$ than females $(60.0 \%)$ by Day 60 (Males: $n=25$, Females: $n=20, p=0.0397$, Log-rank (Mantel-Cox)). C) All Scnla $a^{A 1783 V / W T}$ mice had hyperthermia-induced seizures while age-matched wild type littermates had no evidence of seizure activity $\left(S c n 1 a^{A 1783 V / W T}: \mathrm{n}=71, \mathrm{WT}: \mathrm{n}=16\right)$. D) There was no

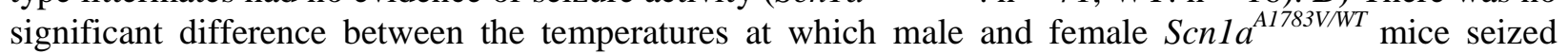
(Males: $\mathrm{n}=43$, Females: n=28, p = 0.959, Log-rank (Mantel-Cox)). 
Pernici, 26
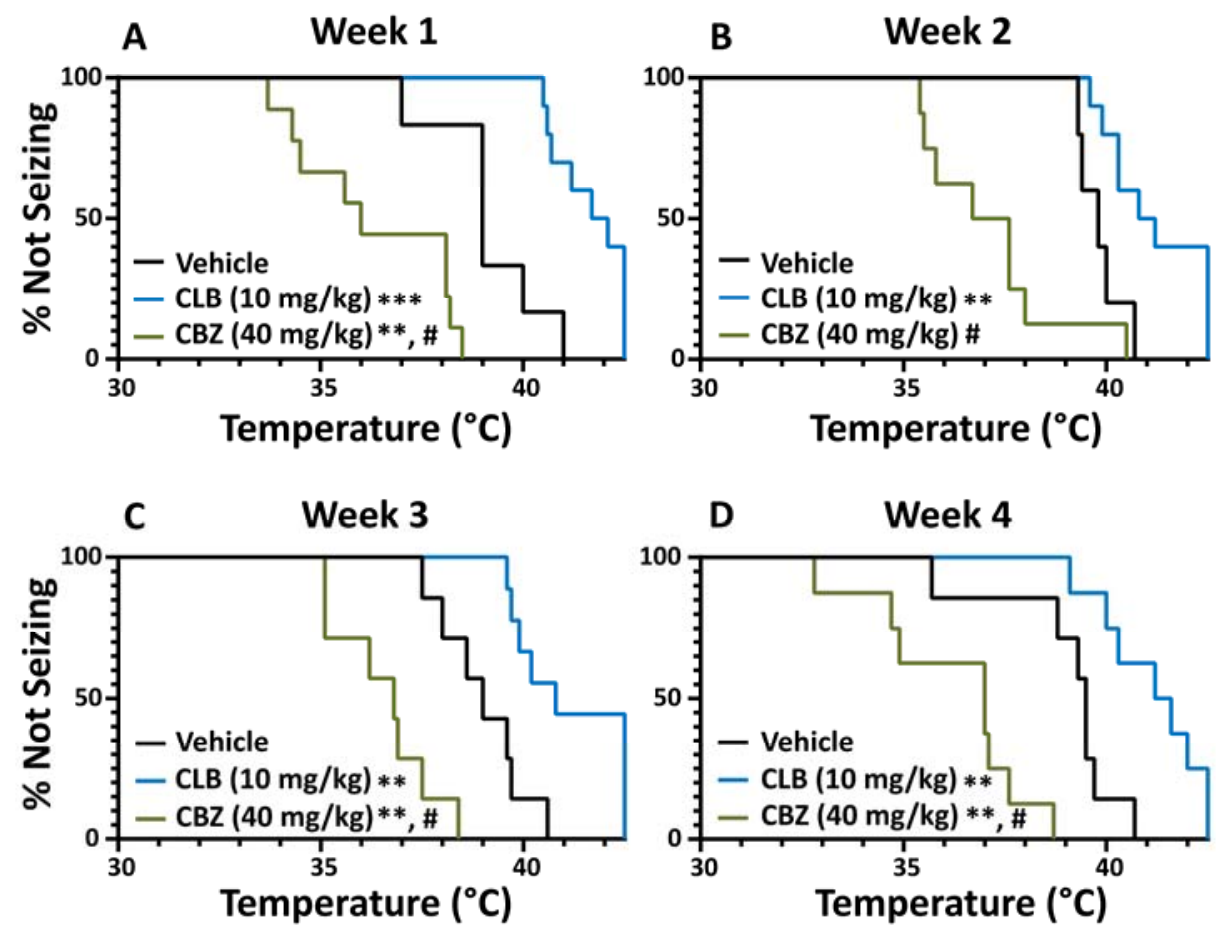

Figure 2. Repeat testing in a weekly crossover design does not change pharmacological outcome of seizures in Scn 1a ${ }^{A 1783 V / W T}$ mice. Scnla $a^{A 1783 V / W T}$ mice were randomly divided into three initial treatment groups (vehicle, CLB, and CBZ). Each week, mice were given a treatment not previously administered. At each week, CLB significantly increased the temperature threshold for which mice had hyperthermia induced seizures when compared to vehicle treated mice (Week $1 \mathrm{p}=0.0005$, Week $2 \mathrm{p}=0.0076$, Week 3 $\mathrm{p}=0.0027$, Week $4 \mathrm{p}=0.0048$, Log-rank (Mantel-Cox)). Alternatively, CBZ decreased the temperature threshold each week, with a significant reduction seen at Week 1, 3, and 4 (Week $1 \mathrm{p}=0.0022$, Week $2 \mathrm{p}$ $=0.051$, Week $3 \mathrm{p}=0.0014$, Week $4 \mathrm{p}=0.0053$, vs. vehicle, Log-rank (Mantel-Cox)). At each week, CLB significantly increased the temperature threshold as compared to CBZ (Week 1-4, p <0.0001, Logrank (Mantel-Cox)). Vehicle: Week 1: $\mathrm{n}=6$, Week 2: $\mathrm{n}=4$, Week 3: $\mathrm{n}=7$, Week 4: $\mathrm{n}=7$; CLB: Week 1: $\mathrm{n}=10$, Week 2: $\mathrm{n}=10$, Week 3: $\mathrm{n}=9$, Week 4: $\mathrm{n}=8$; CBZ: Week 1: $\mathrm{n}=9$, Week 2: $\mathrm{n}=8$, Week 3: $\mathrm{n}=7$, Week 4: $\mathrm{n}=8 ; * * \mathrm{p}<0.01, * * * \mathrm{p}<0.001$ vs. vehicle, $\# \mathrm{p}<0.0001$ vs. CLB. 
Pernici, 27
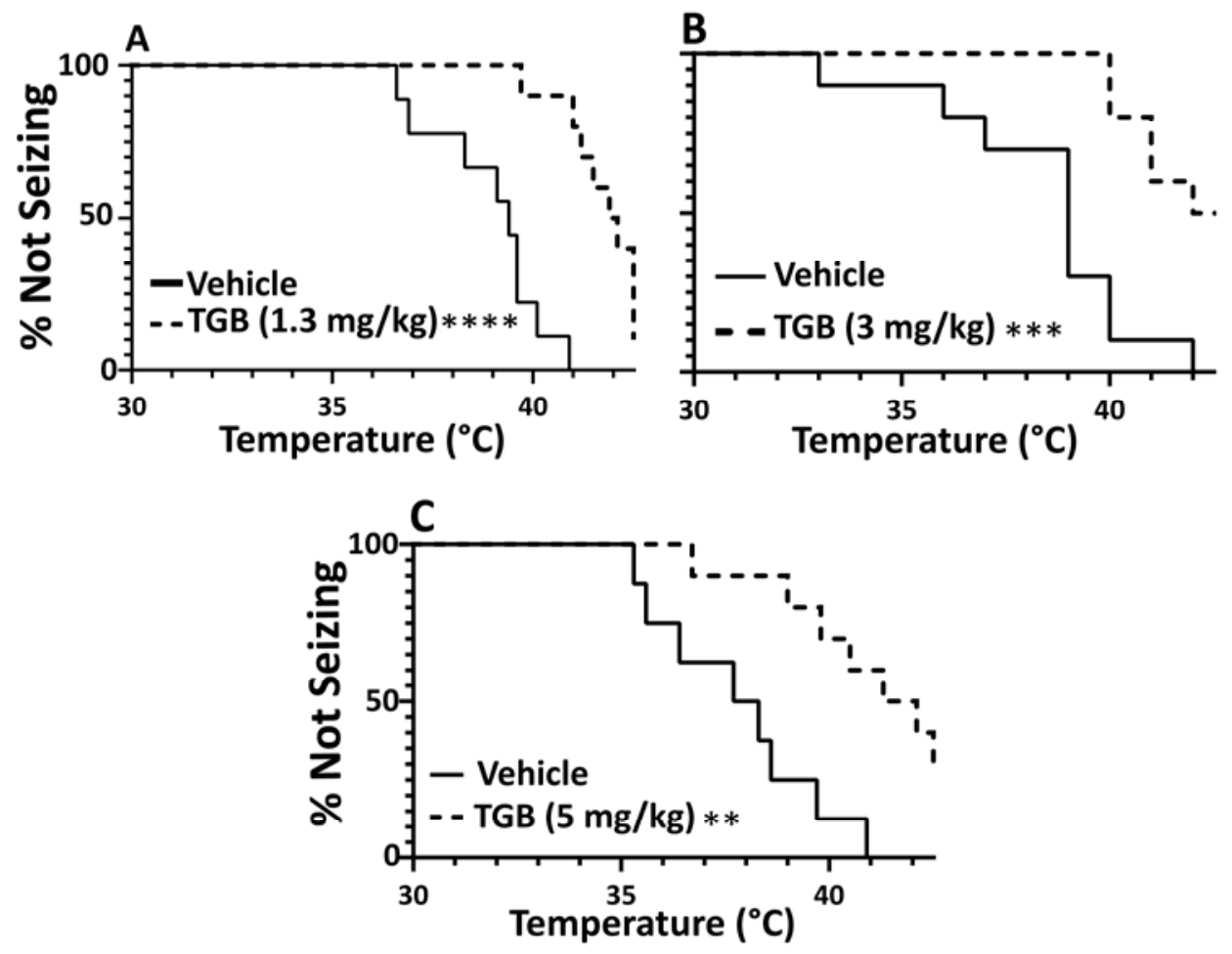

Figure 3. Evaluation of TGB. TGB was evaluated at three different doses to determine the temperature thresholds for hyperthermia-induced seizures. A) A dose of $1.3 \mathrm{mg} / \mathrm{kg}$ significantly increased the temperature threshold at which mice seized as compared to vehicle $(\mathrm{p}<0.0001)$, with $1 / 10$ mice completely protected against hyperthermia-induced seizures. Vehicle: $\mathrm{n}=9$; TGB $(1.3 \mathrm{mg} / \mathrm{kg}): \mathrm{n}=10$ B) A dose of $3 \mathrm{mg} / \mathrm{kg}$ significantly increased the temperature at which mice had hyperthermia-induced seizures as compared to vehicle ( $\mathrm{p}=0.0003$ ), with $3 / 9$ mice demonstrating complete protection. Vehicle: $\mathrm{n}=10$; TGB $(3 \mathrm{mg} / \mathrm{kg}): \mathrm{n}=9 \quad$ C) A dose of $5 \mathrm{mg} / \mathrm{kg}$ significantly increased the temperature at which mice had seizures $(\mathrm{p}=0.0014)$, with $3 / 10$ showing complete protection. Vehicle: $\mathrm{n}=9$; TGB $(5 \mathrm{mg} / \mathrm{kg}): \mathrm{n}=10 \quad * * \mathrm{p}<$ $0.01, * * * \mathrm{p}<0.001, * * * * \mathrm{p}<0.0001 ;$ Log-rank (Mantel-Cox). 
Pernici, 28
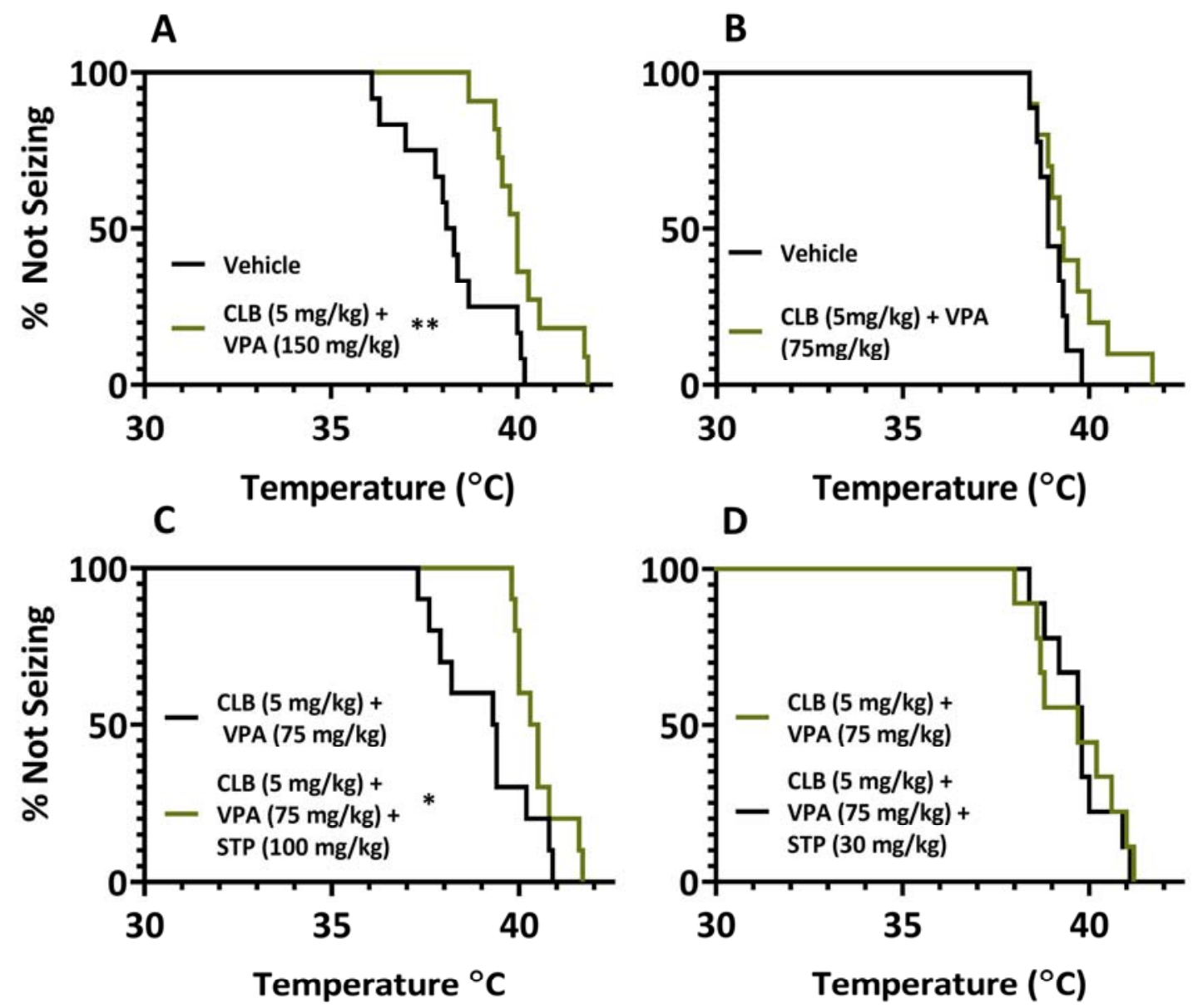

Figure 4. Add-on therapy for the treatment of Dravet Syndrome. A) CLB (5 mg/kg) and VPA (150 $\mathrm{mg} / \mathrm{kg}$ ) treatment significantly lowered the temperature threshold of hyperthermia-induced seizures as compared to vehicle treated mice (Vehicle: $\mathrm{n}=12$, CLB + VPA: $\mathrm{n}=11, \mathrm{p}=0.0060)$. B) CLB $(5 \mathrm{mg} / \mathrm{kg}$ ) and VPA $(75 \mathrm{mg} / \mathrm{kg})$ did not significantly lower the temperature at which Scn $1 a^{A 1783 V / W T}$ mice had hyperthermia-induced seizures as compared to vehicle treated mice (Vehicle: $n=9$, CLB+VPA: $n=10$, $\mathrm{p}=0.1511)$ C) The three drug combo of CLB $(5 \mathrm{mg} / \mathrm{kg})$, VPA $(75 \mathrm{mg} / \mathrm{kg})$ and STP $(100 \mathrm{mg} / \mathrm{kg})$ offered significant protection against hyperthermia-induced seizures as compared to CLB ( $5 \mathrm{mg} / \mathrm{kg})+$ VPA (75 $\mathrm{mg} / \mathrm{kg}$ ) treated $S c n 1 a^{A 1783 V / W T}$ mice (CLB+VPA+STP: $\left.\mathrm{n}=10, \mathrm{CLB}+\mathrm{VPA}: \mathrm{n}=10, \mathrm{p}=0.0471\right)$. D) CLB (5 $\mathrm{mg} / \mathrm{kg})+\mathrm{VPA}(75 \mathrm{mg} / \mathrm{kg})+\mathrm{STP}(30 \mathrm{mg} / \mathrm{kg})$ did not significantly the temperature at which mice seized as compared to CLB $(5 \mathrm{mg} / \mathrm{kg})+\mathrm{VPA}(75 \mathrm{mg} / \mathrm{kg})$ treated mice (CLB + VPA + STP: $\mathrm{n}=9$, CLB + VPA: $\mathrm{n}=9 \mathrm{p}=0.7973) * \mathrm{p}<0.05, * * \mathrm{p}<0.01 ;$ Log-rank (Mantel-Cox). 
bioRxiv preprint doi: https://doi.org/10.1101/2020.12.01.406470; this version posted December 2, 2020. The copyright holder for this preprint (which was not certified by peer review) is the author/funder, who has granted bioRxiv a license to display the preprint in perpetuity. It is made available under aCC-BY-NC-ND 4.0 International license.

Pernici, 29 